\title{
STABLE SEMINORMS REVISITED
}

\section{Richard AREnS, Moshe GoldBerG* ${ }^{*}$ AND W. A. J. LUXEMBURG}

Abstract. A seminorm $S$ on an algebra $\mathscr{A}$ is called stable if for some constant $\sigma>0$,

$$
S\left(x^{k}\right) \leqslant \sigma S(x)^{k} \text { for all } x \in \mathscr{A} \text { and all } k=1,2,3, \ldots
$$

We call $S$ strongly stable if the above holds with $\sigma=1$. In this note we use several known and new results to shed light on the concepts of stability. In particular, the interrelation between stability and similar ideas is discussed.

Mathematics subject classification (1991): 15A60, 47A30.

Key words and phrases: Algebras, norms, seminorms, stability, strong stability.

\section{REFERENCES}

[AG1] R. ARens And M. Goldberg, Multiplicativity factors for seminorms, J. Math. Anal. Appl. 146 (1990), 469-481.

[AG2] - A class of seminorms on function algebras, J. Math. Anal. Appl. 162 (1991), 592-609.

[AG3] Weighted $l_{\infty}$ norms for matrices, Linear Algebra Appl. 201 (1994), 155-163.

[AG4] Homotonic mappings, J. Math. Anal. Appl. 194 (1995), 414-427.

[AG5] W Weighted $l_{1}$ norms for matrices, Linear and Multilinear Algebra 40 (1996), 229-234.

[AGL1] R. ARENS, M. GoldBerg AND W. A. J. LuXEMBURG, Multiplicativity factors for function norms, J. Math. Anal. Appl. 177 (1993), 368-385.

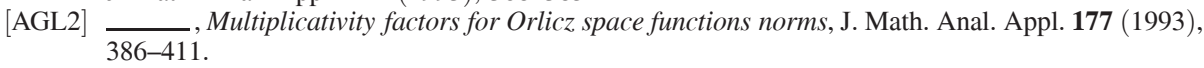

[FZ] S. FRIEDLAND AND C. ZENGER, All spectral dominant norms are stable, Linear Algebra Appl. 58 (1984), 97-107.

[GT] M. GOLDBERG AND E. TADMOR, On the numerical radius and its applications, Linear Algebra Appl. 42 (1982), 263-284.

[H] P. R. Halmos, A Hilbert Space Problem Book, Van Nostrand, New York, 1967.

[P] C. PEARCY, An elementary proof of the power inequality for the numerical radius, Michigan Math. J. 13 (1966), 289-291. 